\title{
ARTICLE
}

\section{Challenging Spaces: Liminal Positions and Knowledge Relations in Dynamic Research Partnerships}

\author{
*Patric Wallin and Liselott Aarsand, Department of Education and Lifelong Learning, \\ Norwegian University of Science and Technology (NTNU), Norway
}

Contact: Patric.wallin@ntnu.no

\section{ABSTRACT}

This article draws upon concepts of liminality and Third Space to explore what happens when undergraduate students become research partners and illustrates how various positions emerge, change, and fluctuate within the educational space of an interdisciplinary course. Based on perspective dialogues with student groups who have worked on research projects concerned with learning environments in higher education, we discuss which experiences from various academic spaces the students make relevant and use as resources in their group work. Furthermore, we highlight how the act of challenging traditional knowledge hierarchies and well-established roles also involves a revision of students' relations to each other.

\section{KEYWORDS}

third space, liminal positions, undergraduate research experiences, dynamic student relations, higher education research

Contemporary debates on higher education reveal an interesting ambition to base approaches to teaching and learning on empirical evidence (Perry \& Smart, 2007). With this in mind, one main concern is to consider how research on higher education is conducted, who influences its direction, and what questions are being raised. While students traditionally are involved in academic development efforts as informants (Lizzio, Wilson, \& Simons, 2002), they are much less involved in conducting research on higher education during their time as students. In the present article, we will use a qualitative research approach to explore what happens when undergraduate students become researchers within the educational space of an interdisciplinary course.

The involvement of students in research has been discussed in broad terms and various settings, and Healey (2005) has introduced a framework to pinpoint different ways of linking and integrating teaching and research. One particular approach that is widely used in this regard involves undergraduate research experiences (UREs), where the students are the researchers (Brew, 2013; Lopatto, 2003). There is a growing body of literature focusing 
on this type of inquiry, demonstrating that it facilitates the students' intellectual development and increases their higher-order thinking skills (Brew, 2003; Hodge, Magolda, \& Haynes, 2009; Levy, 2011; Wallin, Adawi, \& Gold, 2017). UREs are, however, predominantly offered in the science, technology, and engineering fields, and with few exceptions situated within one or closely related disciplines (Brew, 2013). Furthermore, there is often little space for either pedagogical negotiations concerned with the positions and roles that teachers and students have within UREs, or for critical discussions between students and teachers of the epistemological and methodological groundings of the research activities.

Bearing this in mind, there is an apparent need to undertake careful and critical empirical research that may contribute to this field. One way to address and emphasise the importance of pedagogical negotiations and discussions, as well as critical engagement with research and research methods, is to focus on student-teacher partnership or Students-asPartners (Cook-Sather, Matthews, Ntem, \& Leathwick, 2018; Cook-Sather, 2014; Healey, Flint, \& Harrington, 2014). Here, a partnership is based on a reciprocal relationship between the student and the teacher, where both benefit and accept certain risks by engaging in something that is not fully predicable (Healey et al., 2014; Marquis et al., 2016). A partnership positions students as knowledgeable partners who contribute to and shape their learning experiences (Healey, O'Connor, \& Broadfoot, 2010; Jensen \& Bennett, 2016). Neary and Winn (2009) have taken this even further by introducing the term Student as Producer, which emphasises "undergraduate students working in collaboration with academics to create work of social importance that is full of academic content and value, while at the same time reinvigorating the university beyond the logic of market economics" (p. 193). By re-considering the relationship between undergraduate teaching and academic research, the concept of Student as Producer offers opportunities to re-establish the university as a place for collaboration between students and academics with the common purpose to produce knowledge and meaning (Neary, 2010, 2012, 2016).

Moreover, Jensen and Bennett (2016) argue that "the way that this occurs is through the use of dialogue to develop mutual understanding" (p. 42). Dialogue should, however, not be understood as a mere technique, but as part of the developmental process in becoming knowledgeable partners and human beings - "a moment where humans meet to reflect on their reality as they make and remake it" (Shor \& Freire, 1987, p. 13). Such a definition of partnership reflects the principles and values of authenticity, reciprocity, being more, hope, and responsibility. The link between Freirean pedagogy and Students as Partners is important as it provides foundational values that can counteract neoliberal, domesticating, and technocratic threats to meaningful partnership (Peters \& Mathias, 2018).

In addition to the potential of Students as Partners and Students as Producers to stimulate dialogue, discussions, and negotiations, Jensen and Bennett (2016) highlight the importance of "repositioning the way that students can contribute to teaching and learning through including and valuing their perspectives and experiences and by students taking a more active role and leading activities in relationship with staff" (p. 42). Creating opportunities for this type of partnership in higher education means acknowledging both students' and teachers' hybrid positions, thereby rejecting such binaries as student and teacher, student and researcher, and research-producer and research-consumer, amongst other potential relations and positions (Cook-Sather, 2014; Healey et al., 2014; Neary, 2010). By challenging traditional positions and encouraging student-teacher partnerships 
that explore pedagogical practices, new forms of higher education research and academic development can emerge (King, Kersh, Potter, \& Pitts, 2015; Werder, Thibou, \& Kaufer, 2012; Neary, 2012).

Positioning students as knowledge producers is an important step that moves beyond research on students and research with students to research by students. As such, students' positions emerge as central rather than additional, which may disrupt traditional forms of knowledge construction. It could be argued that such research is a key issue, not only for new forms of academic development and research, but also in more fundamental ways as it potentially addresses the dynamics of knowledge relations and knowledge hierarchies in negotiating what is held to be valid and "true." By creating a "semi-permeable membrane between students' mediated cultures and the culture of the classroom" (p. 85), a more porous exchange of expertise can be supported, where students may contribute their resources to conduct research on higher education (Potter \& McDougall, 2017). In what has been called Third Space (McDougall \& Potter, 2015), the traditional positions of teachers and students are dissolved and both can occupy liminal positions that challenge assumptions and frames of reference in new ways (Cook-Sather \& Alter, 2011). Liminal positions may be described as "ambiguous, neither here nor there, betwixt and between all fixed points of classification" (Turner, 1974, p. 232) and can be used to depict inbetweenness as an important part of creating a Third Space (Barrineau \& Anderson, 2018). In this way, the Third Space can be described as "a transformative space where the potential for an expanded form of learning and the development of new knowledge are heightened" (Gutiérrez, 2008, p. 152).

With these perspectives serving as our backdrop, in the present article we will draw upon dialogues with students who work in groups on research projects that address how learning environments in higher education may be improved. We will in particular explore what happens when undergraduate students become researchers and illustrate how various positions emerge, change, and fluctuate within the educational space of an interdisciplinary course. A key interest is to highlight how the act of challenging traditional knowledge hierarchies and well-established roles also requires a revision of the students' relations to each other and the emerging dynamics within the students' work groups. By making experiences from inside and outside higher education relevant in their group work and using them as resources for sense-making, the students create a space with the potential to transform relationships between student and student, as well as between student and teacher.

\section{CONTEXT AND CASE}

The context for this study is the interdisciplinary course Environments for Learning in Higher Education, a 7.5-ECTS (European Credit Transfer and Accumulation System) course that falls under the Experts in Teamwork (EiT) umbrella at the Norwegian University of Science and Technology (NTNU) in Norway. Courses under the EiT umbrella share an experience-based interdisciplinary approach with a focus on students' development of collaborative skills and reflective capacity but have different disciplinary groundings and topics that students work with. EiT is mandatory for most Master's level students at NTNU, meaning that students from all disciplines are taking a course under the EiT umbrella. In total at NTNU, around 80 to 90 courses under the EiT umbrella are held each year with over 2500 students (see Wallin, Lyng, Sortland, \& Veine, 2017 for further details on EiT). 
Environments for Learning in Higher Education has 20 to 30 Master's students from various study programmes working in groups of five over a period of 15 weeks. Student groups have weekly full-day (8:00-16:00) meetings on a self-defined research project coupled to the overall theme of the course. Examples of research projects include: How to Create an Inclusive University Environment; Identity places: Balancing Disciplinary Belonging and Interdisciplinary Collaborations; and Insights into Active Learning and Physical Learning Environments in Higher Education. The aim is that by defining, planning, and running their own research projects, students can raise questions about university learning environments that they deem important and remain in control as to how to conduct and frame their research. During the weekly meetings, students work on their group projects in a selfdefined manner and the teacher acts similar to a dialogue partner and critical friend (Costa \& Kallick, 1993) to provide additional perspectives to the students' ideas and approaches, as well as reoccurring formative feedback on their project reports.

The resulting final project reports are graded on the group level, but more importantly the reports are a relevant resource for academic development at NTNU and are highly valued by central administration, which is working on developing and planning a new campus for the future. As such, all the projects have meaning beyond the course, which indeed positions students as knowledge producers and makes their work available to the local community, as well as worldwide. Examples of NTNU student research projects on learning environments have been compiled in digital archives (see http://patricwallin.org/student-research/).

\section{METHODS AND DATA}

This article was co-authored by two academics who have started from different points of departure when approaching liminal positions and knowledge relations in dynamic research partnerships. Patric Wallin is a post-doctoral fellow in university pedagogy and has taught the course Environments for Learning in Higher Education in 2017 and 2018. Liselott Aarsand is a professor with a particular interest in adult learning, subjectification, and social norms and order in everyday practices.

An integral part of the Environments for Learning in Higher Education course are perspective dialogues that aim to help students gain new perspectives on their individual and group development at the end of the course. The dialogues focus on four themes: group dynamics, doing research, interdisciplinary teamwork, and report writing. Similar to focus-group interviews, the aim is to capitalise on communication between students in order to stimulate memories and reflections on experiences (Bhattacherjee, 2012). At the same time, the teacher (Patric Wallin) offers his thoughts after listening to the students in a more dialogic format to encourage further discussions and reflections. Through this dialogic approach, students may be able to see their own development from new perspectives and gain deeper insights. The perspective dialogues last from around 45 to 90 minutes.

In this research project, the students were asked for their informed consent to audio record the perspective dialogues and to use the dialogues in research. All the students agreed to participate in the research project. The perspective dialogues were held in Norwegian and each dialogue was transcribed soon after the event. Only the passages used in the present paper have been translated into English, where all the students have also been given pseudonyms.

The empirical material was analysed using a qualitative approach with Third Space as a sensitising concept with the aim of generating meaning and developing categories. 
Accordingly, the analysis was particularly guided by how various forms of knowledge and knowledge relations were made relevant, negotiated, and acknowledged across the data. The material was read, re-read, and discussed several times by the authors to discover accounts where the students relate their own subjectivity and positioning with respect to themselves, each other, and the teacher. During this phase, one of the author's experiences as a teacher of the course played an important role and were thus integrated with the students' accounts from the perspective dialogues. However, in and through collaboration between the authors, these experiences were also challenged, thus making it possible for the teacher to approach the material as a researcher rather than a teacher. Furthermore, two themes emerged from the analysis that we will address in the upcoming sections: creating space for liminal positions and creating space for interdisciplinary negotiations. Each theme will be illustrated with excerpts from the perspective dialogues.

\section{ANALYSING PERSPECTIVE DIALOGUES: CHALLENGING SPACES}

The first phase of the Environments for Learning in Higher Education focus on how to create and establish genuine collaborative work modes. To accomplish this, the students map their competencies and interests within their work groups and discuss how they want to work on their projects. The teacher provides general information about the course, frames the overall theme for the projects, and engages in a dialogue with the students to start the process of establishing partnerships and building trust. Accordingly, a key issue is to encourage a move beyond the more traditional roles of teacher and student, which means allowing for the emergence of liminal positions involved in collaborative knowledge production. However, it can be challenging to initiate, re-shape, and negotiate various positions that are relevant in this context, not least since they not only include the studentteacher relationship, but also involve a revision of the students' relations to each other and the dynamics within the work groups. Hence, highlighting how the students negotiate their identity as students with other students within the realm of creating and establishing Students-as-Partners relationships will be a main approach in the upcoming analysis. It can also be argued that this is complex relational work of key importance that may also have something to say for facilitating the development of new kinds of partnerships with academics.

\section{Creating space for liminal positions}

The perspective dialogues demonstrate that the students depicted the course as a site where the work group, its relations, and processes are considered to be fundamental. Working in groups within the context of higher education was far from new for the students. However, positioning oneself and each other as pivotal in the emerging process and product, thus highlighting the importance of truly working together, was not necessarily a familiar approach for all the students. As opposed to what the students might have expected, the situation claims a student subjectivity in which dialogue and collaboration are crucial, and where positioning oneself as a resourceful group member and contributing to knowledge production is of great importance. As illustrated by Clara, the students initially felt that this course encounter differs from how they usually dealt with similar situations where group work was part of the agenda:

Clara: One thing I've learned a lot from is the importance of this start-up phase that we had in the project. First, I thought it was a bit pointless and frustrating when we just focused on getting to know each other. But now I don't really think, even if we 
get along nicely, I don't think we would have had so much fun without this period. And I know for sure that if we had been given project tasks already from the start, even though you would have told us not to focus on them, we would have been focusing on them anyway. So, it was frustrating at the start, and unclear what we should do- "We're on day four and we still have no idea"-but I really think that was smart because there was plenty of time to really get to know each other. And the focus came a little later. (Perspective dialogue, Group 2)

This extract reveals an ambivalent attitude where the work forms and requirements for a slightly changed student position are not immediately appreciated. Clara expresses how she struggled and in fact found the initial phase "pointless" and "frustrating," which led her to more or less question the whole idea. Usually, when faced with group work in higher education, students are expected to be goal-oriented and effective, which accentuates an instrumental focus on the assignments given. Clara describes how this appears to be almost taken for granted and claims that despite whatever instructions teachers may give at the beginning of a project, "we [the students] would have been focusing on them [the project tasks] anyway." Apparently, the attention given to focusing on building relationships and engaging in collaboration that is highly prevalent in this course falls short of such expectations grounded in previous educational experiences. Some of the students, such as Clara, would probably have felt more comfortable within the former more familiar framing, not least so they could have a feeling of being productive. Instead, she saw day after day passing by while the student group was stuck. Hence, the quote illustrates how Clara and her peer students wrestled with how to assume their identities as students within this new context.

As the process progressed, however, the students seemed to change their attitude, which Clara describes by referring to how she slowly took an opposing stance to her initial opinion: "I really think that [the course design] was smart because there was plenty of time to really get to know each other." Drawing upon Clara's reflection, we can see that a shift in focus is revealed where the students have to position themselves as the knowledgeable ones. Hence, the course framing requires that the students assume the role of knowledge producers rather than consumers, which means that they are supposed to bring their personalities, strengths, and probably also weaknesses into this educational space. Even though being a condition for the emerging knowledge production, it nevertheless appears to be a quite self-evident and simple task. It should also be noticed that a majority of the students work in the course with an open mindset about how things might be different here. This pre-disposition to explore, experiment with, and negotiate what appears to be slightly different positions, at least compared to a more traditional student role, is an important resource that the students bring into this space.

Creating an educational space where the students feel they can share their ideas, assume different positions, and discuss their thoughts is a core element in the course. The students focus keenly on how such forms of work embrace a permissive environment, and how that could condition their project. While collaboration is initially described as challenging, it is eventually found to be rewarding, at least when looking at it retrospectively during the perspective dialogues:

Maria: So, I think maybe because we-we had so much time during the first four to five project days. There was room for discussions like, "You can discuss your research 
question a bit, but you do not need to come to any conclusion." So, we continued to do this throughout the project. Probably we have discussed everything and anything to death. Because we had time for it at the start, it has become a bit of an approach we have continued with.

Lisa: So, if everything would have been strict and hard from the start, then that would have set the trend. But then I think this has been important too, because it's important to spend some time discussing - and to have a nice time. . . . So, in a way we needed to just have that approach. At least occasionally, but we maybe could have had a little less discussion sometimes.

Sven: The question is if it would have been the same good atmosphere within the group if we had just started directly. Because there has always been a really nice atmosphere.

Lisa: All the other group projects I've ever been in never have had a good atmosphere. They were stressful, nagging, scolding, and full of conflicts-people have hated each other. So from that point of view, it is refreshing to have a nice time for once. And there is normally a lot of stress from time pressure that makes it so difficult, because you don't have time to make, to take care of each other, and to use each other's abilities and thoughts as resources. (Perspective dialogue, Group 3)

Maria describes how the collaborative work form, although sometimes both challenging and exhausting, became the preference within the student group throughout the entire process. With a hint of irony, she states that "probably we have discussed everything and anything to death," and in this way depicts how every detail seems to have been characterised by co-creation. Two other members in her group, Lisa and Sven, continue to elaborate on this by highlighting their experience of a friendly atmosphere within the group. According to these students, this is not necessarily always the case when working in groups in higher education. What they have experienced is depicted as an exceptional case where it is "refreshing to have a nice time for once."

What also emerges in the perspective dialogues is how the permissive culture in the group is crucial for further exploring each other's individual qualities. The excerpt shows how Sven emphasises the "same good atmosphere" throughout the whole process, and he also claims that the initial move into the project was decisive. This is further illustrated by Lisa, who agrees and draws upon her extensive experience of group work in higher education and how she usually finds it to be "stressful, nagging, scolding, and full of conflicts," and she even claims that "people have hated each other," which is in sharp contrast to what she feels now. The negative experiences from group work in general, Lisa explains, are due to a lack of time, and she further describes the advantage of how a friendly environment makes it possible to acknowledge the various understandings they all bring into this context.

The perspective dialogues, then, demonstrate that individuality and diversity seem to emerge as part of such collaborative dynamics. It appears possible, and probably even necessary, for the students to position themselves and take responsibility as individuals revealing their own opinions, experiences, and ideas, and to give voice to their values, habits, and preferences. Or, as another student, Edwin, put it: "I feel that I have learnt a lot about myself" (Perspective dialogue, Group 1), which could be argued demonstrates a transcendence of a more traditional student subjectivity and also reveals how learning is usually about other things than oneself. 
Taken together, the educational space co-created by the student and the teacher points to partnership and collaboration as being crucial to knowledge production. From the perspective dialogues, it appears that it is challenging to revise and negotiate various positions that are relevant in this context, which highlights the students' relations to each other and the emerging dynamics within the student work groups. By highlighting the group and its members as fundamental to the work process, the students are tied together as partners rather than having a strong focus on the teacher.

\section{Creating space for interdisciplinary negotiations}

The educational space created in and through the course enables dialogues on the nature of knowledge and research, and these questions then play an important role in the emerging work and shape the learning experiences. Cultivating the idea of inviting the students to take part in research and knowledge production rather than knowledge consumption means stimulating them to take their own decisions along the way, prompting them from time to time with questions, and having perspective dialogues at the end. Accordingly, this pedagogical design also accentuates questions on the nature of research and what counts as valid knowledge. It could be argued that the partnership process allows for interdisciplinary negotiations, which also illustrates the agency, knowledgeability, and authority performed when making sense of and evaluating educational practices and research in higher education.

In focusing the discussions on what may count as valid research and knowledge, an interdisciplinary negotiation emerges among the students where they make particular experiences available, and share and use them as resources to frame opinions and make decisions. Looking into the perspective dialogues, there is no doubt that the students drew upon the various academic traditions to which they belonged, as well as everyday orientations, to claim what holds as "true." Even though the students may lack an advanced frame of reference, they nevertheless took clear stances, which positioned them as coproducers and knowledgeable actors. When invited to reflect upon what kind of work they were engaged in, and if such processes may be considered as valid research, multiple stances arose:

Daniel: I would say yes, we've done that.

Sven: Find out something new.

Lisa: No, we haven't done anything like that. We've just talked to people and found out what they've said. That's, what it's called, social science, no not social science, humanities, maybe. (Perspective dialogue, Group 3)

As illustrated in the excerpt, Daniel claims that the student group has accomplished something that may be conceptualised as research. Another student in his group, Sven, agrees and elaborates on why this is the case by adding that "find[ing] out something new" is a characteristic of research, which according to him is what the student group has been involved in. On the other hand, Lisa takes an opposing stance and argues that research work is in fact something else. Seemingly, Lisa's frame of reference for what counts as valid research prevents her from understanding that the knowledge production she and her peer students have been engaged in is indeed research, which leads her to claim that the group was merely able to capture people's experiences and understandings. In eventually making 
a slight shift, Lisa then claims that it may, however, be seen as research when located in disciplines distinct from the one to which she belongs.

A key issue, then, in how the students talked about and examined their processes and projects is to some extent ambiguity, where it becomes apparent that they are not entirely sure how their work is to be considered, what research in fact is, and what counts as valid knowledge. At the same time, the students also take clear stances in reviewing their work by using particular words to explain what may be seen as characteristic for research. For instance, this is expressed by Julia who argues that their work does not reach research standards since it is not "rigorous or systematic enough to call it research" (Perspective dialogue, Group 2). However, even though these words are recurrently used to put up boundaries between research and other activities, when looking closer into this landscape it becomes quite unclear what meanings and understandings the students in fact assign to such concepts.

Furthermore, when the students discussed and try to clarify what it is that makes research, they make various research methods and methodologies relevant and use them as resources in negotiating what forms of knowledge can be acknowledged and validated:

Lisa: I feel it gets a bit diffuse, and I'm like "is this statistically representative"? Is this anything at all?

Sven: Just that it's not presented in tables.

Lisa: Or that it can't be measured.

Maria: I think I felt your frustration about it a little bit throughout the project. That you have a little number-focused way of thinking from time to time. And that I see, I have an approach, where I see both aspects, because I have both qualitative and quantitative methods in my studies. But yes, so it's been a bit like that. Perhaps a little hard to convince you-no, it hasn't been very hard to make you see that the qualitative approach also works.

Lisa: It's been fun in a way. It's been nice to hear someone say something and not just look at numbers. I think. But I'm a little bit confused about it. But the point is that it doesn't feel good enough.

Daniel: I feel, it's just that I haven't done it before. I don't know if this is good enough. It's just that I'm unsure. But I have very, of course I have confidence in it. It's just my own insecurity. (Perspective dialogue, Group 3)

As illustrated in the excerpt, Lisa's rhetorical question-asking if the student groups' work is "anything at all"-points out a struggle to fully know how to adequately examine the quality of this work. In negotiating what counts as valid knowledge and research, many of the students use terms taken from a science research genre by drawing on such language as "representative," "statistics," "numbers," and "tables." Maria, who is familiar with the social sciences, explains that she felt frustration among her engineering and science peer students throughout the project. Separate from them, she positions herself as somebody who has experience with quantitative as well as qualitative research approaches, which she claims to be useful knowledge that makes it easier for her to acknowledge their work process as quite close to research.

It can also be noticed that some of the students point out that their work has been particularly interesting in the sense of trying out new ways to produce knowledge. In this excerpt, for instance, Lisa, enthusiastically says, "it's been fun in a way, it's been nice to hear 
someone say something and not just look at numbers" and further adds that she is nevertheless slightly "confused" when confronted with various disciplines and knowledge domains. Daniel agrees with Lisa and expresses how encountering something unfamiliar also raises the question of insecurity: "I don't know if this is good enough," he says. As such, it could be argued that the students are put in a position where they are encouraged to (re)consider their frames of reference and their conceptual understandings of what knowledge and research in fact may be.

Taken together, the educational space provided appears to allow students to relate to their own work in multiple ways. There is no doubt that distinct experiences, approaches, and stances on how to characterise and examine knowledge and research became part of the discussions among the students in the work groups, and that discussion of these topics was also triggered by the perspective dialogues. When working across and between knowledge domains and classifications there is a risk of ending up with rather messy spaces. The dialogues also illustrate that there is probably a need to draw and maintain some boundaries and characteristics that distinguishes research from similar activities, which may facilitate the development of quite "rough" definitions of research. Nevertheless, encouraging such dialogues highlights the students as partners, co-producers, and knowledgeable actors in these types of occasional communities addressing extensive questions on knowledge and research, and such discussions may be seen as relevant for higher education as well as for society in general. Hence, the space created for interdisciplinary negotiations and the liminal positions emerging within this space may have transformative potential.

\section{DISCUSSION AND CONCLUDING REMARKS}

In the discussion we would like to focus on how partnership can contribute to an educational space where students and teachers assume liminal positions and begin to challenge well-established divisions of roles and knowledge hierarchies

In contrast to a majority of efforts present in the partnership literature (Cook-Sather et al., 2018; Barrineau \& Anderson, 2018) and the Third Space literature (Han, McDougall, Mott, \& Sudbury, 2018; Pitts \& Brooks, 2017), the educational space described here was created amongst students from different disciplines within a particular course setting. We argue that it is interesting to explore this type of setting, not least since courses remain the dominant organisational format for the university's formal learning activities.

Furthermore, distinct from extra-curricular activities, courses allow for more inclusive and open forms of partnership by involving students who otherwise would not participate in activities linked to higher education research and academic development. The approach described here has the potential to create a space for transgressive negotiations with a diverse group of students whose voices otherwise might not be heard and to mitigate the risk of a commodification of partnership, where students become involved to improve their formal qualification (Cates, Madigan, \& Reitenauer, 2018; Potter \& McDougall, 2017).

At the same time, there is still a risk that the authority of the teacher and the epistemological hierarchy are maintained by framing this educational space within a course (Potter \& McDougall, 2017; Routledge, 1996). By building on principles from Freirean pedagogy and emphasising dialogue as a central element both between students and between students and teachers, we tried to counteract potential domesticating and technocratic threats (Peters \& Mathias, 2018). However, we acknowledge that the course setting creates challenges that are connected to its structural and organisational boundary 
conditions, as well as the expectations that participants bring with them to the course and the cultures that are situated within it (Bovill, Cook-Sather, Felten, Millard, \& Moore-Cherry, 2016). In future research, our ambition is to take a closer look at the boundary conditions created by the course and further explore how power relations are established, negotiated, and played out within this space.

The educational space that this article describes demonstrates that partnership and collaboration are crucial to knowledge production, which appears to allow students to relate to their own work in multiple ways. The interdisciplinary nature of the course appears to be an important condition for how it enabled the students to bring a large variety of resources with them from their diverse study backgrounds. Furthermore, the students' different experiences of group work and understandings of research provided contrasts that they drew upon to discuss, negotiate, and (re)consider their frames of reference for how to work together, as well as for understanding the nature of knowledge and research. Through the porous exchange of expertise, the students could position themselves as knowledgeable and take responsibility as individuals revealing their own opinions, experiences, and ideas (Potter \& McDougall, 2017). We further argue that by negotiating the nature of knowledge production and the definition of research in their own work, the students started to establish a common ground to reconnect the natural and social sciences. It is through these interdisciplinary negotiations that students experience and contribute to the "creation of one science" (Neary, 2012, p. 3).

We argue that students used their differing perspectives as a starting point to create a strong partnership between each other and to establish their group as a primary social space. The creation of this social partnership enabled them to create an environment which affected and potentially dissolved the teacher's position. It becomes apparent from the perspective dialogues that the dialogues and negotiations that students had with each other were a key part of their development. The role of the teacher in this type of partnership is focused on creating opportunities and supporting students to re-consider their expectations and understandings of higher education (Neary \& Winn, 2009). One important aspect for the teacher is to create and co-create an educational space that allows the students to take more liminal positions as research partners by empowering them to work on projects and research questions that are independently developed by the students. As such, this work should be seen as research by students. Another important factor highlighted by the students was that the teacher should create opportunities to interact with stakeholders outside of the course, like academic developers and faculty administration, in order to support them to produce something that is meaningful beyond the course itself.

In contrast to many of the examples described in the partnership literature that focus on a faculty member inviting students into academic development collaboration (Bovill et al., 2016), the approach described here helps students to assume positions as researchers who exercise a high degree of control over their projects. Through students' contribution to research, their voices are elevated in academic development processes that are increasingly based on empirical evidence (Perry \& Smart, 2007). The focus on research creates a semi-permeable membrane that allows meaningful interactions and development of expertise across students' mediated cultures, the culture of the classroom, and academic development. From this vantage point, it is probably also easier for the students to engage in discussions and dialogue with the teacher as partners, not as students influenced by a traditional division of roles. 
The dynamic and fluctuating nature of their own subjectivity and positioning within the course created some confusion and frustration among the students, which has been illustrated in the perspective dialogues. The ambiguity associated with this repositioning is a key feature of partnerships that challenge traditional roles and predictable paths of education (Bovill et al., 2016; Felder \& Brent, 1996). By creating space for liminal positions and for negotiations of research, the potential to transform relationships between teacher and student as well as between student and student is heightened (Barrineau \& Anderson, 2018). It is within this educational space that students can have experiences "with unique potential to challenge deep-seated assumptions about how a community or society works" (Cook-Sather \& Alter, 2011, p. 37). The rejection of binaries, as suggested by the erosion of the positions of student and researcher, and student and teacher, also creates the need to re-consider the notion of Students as Partners (Cook-Sather et al., 2018) and goes beyond a focus on student-staff partnerships. From our work, it is apparent that the student-student dialogues are central for students' experience and development and act as an important pre-emptive strategy for facilitating Students-as-Partners relationships with academics.

All in all, challenging traditional spaces in course settings and designing opportunities for students to engage in higher education research are important steps in creating educational spaces that enable students to make contributions to the future of higher education and society, as well as negotiate knowledge relations in interdisciplinary contexts.

All participants gave their informed consent to be part of this research study, and the project was reviewed and approved by the Norwegian Centre for Research Data (NSD). All the data was processed according to NTNU's internal procedures for maintaining information security.

\section{ACKNOWLEDGEMENTS}

The authors would like to thank all the students who took part in this study and participated in the course and perspective dialogues.

\section{NOTES ON CONTRIBUTORS}

Patric Wallin is an Associate Professor at the Department for Education and Lifelong Learning at the Norwegian University of Science and Technology. His research focuses on personal development, meaningful assessment, and learning environments. He is particular interested in how to create educational spaces that enable students to make meaningful contributions to research and society.

Liselott Aarsand is Professor at the Department of Education and Lifelong Learning, Norwegian University of Science and Technology. Her research focuses on learning, subjectification and social interaction in education and other everyday practices. She is also interested in methodological challenges and analytical work in qualitative research.

\section{REFERENCES}

Barrineau, S., \& Anderson, L. (2018). Learning "betwixt and between": Opportunities and challenges for student-driven partnership. International Journal for Students as 
Partners, 2(1), 16-32. https://doi.org/10.15173/ijsap.v2i1.3224

Bhattacherjee, A. (2012). Social science research: Principles, methods, and practices (2nd ed.). University of South Florida Tampa Bay Open Access Textbooks Collection. Retrieved from

https://scholarcommons.usf.edu/cgi/viewcontent.cgi?article $=1002 \&$ context $=0 a$ textb $\underline{\text { ooks }}$

Bovill, C., Cook-Sather, A., Felten, P., Millard, L., \& Moore-Cherry, N. (2016). Addressing potential challenges in co-creating learning and teaching: Overcoming resistance, navigating institutional norms and ensuring inclusivity in student-staff partnerships. Higher Education, 71(2), 195-208. https://doi.org/10.1007/s10734-015-9896-4

Brew, A. (2003). Teaching and research: New relationships and their implications for inquirybased teaching and learning in higher education. Higher Education Research \& Development, 22(1), 3-18. https://doi.org/10.1080/0729436032000056571

Brew, A. (2013). Understanding the scope of undergraduate research: A framework for curricular and pedagogical decision-making. Higher Education, 66(5), 603-618. https://doi.org/10.1007/s10734-013-9624-x

Cates, R. M., Madigan, M. R., \& Reitenauer, V. L. (2018). 'Locations of Possibility': Critical Perspectives on Partnership. International Journal for Students as Partners, 2(1), 33-46. https://doi.org/10.15173/ijsap.v2i1.3341

Cook-Sather, A. (2014). Student-faculty partnership in explorations of pedagogical practice: A threshold concept in academic development. International Journal for Academic Development, 19(3), 186-198. https://doi.org/10.1080/1360144X.2013.805694

Cook-Sather, A., \& Alter, Z. (2011). What is and what can be: How a liminal position can change learning and teaching in higher education. Anthropology \& Education Quarterly, 42(1), 37-53. https://doi.org/10.1111/j.1548-1492.2010.01109.x

Cook-Sather, A., Matthews, K. E., Ntem, A., \& Leathwick, S. (2018). What we talk about when we talk about students as partners. International Journal for Students as Partners, 2(2), 1-9. https://doi.org/10.15173/ijsap.v2i2.3790

Costa, A. L., \& Kallick, B. (1993). Through the lens of a critical friend. Educational Leadership, 51(2), 49-51.

Felder, R. M., \& Brent, R. (1996). Navigating the bumpy road to student-centered instruction. College Teaching, 44(2), 43-47. https://doi.org/10.1080/87567555.1996.9933425

Gutiérrez, K. D. (2008). Developing a sociocritical literacy in the third space. Reading Research Quarterly, 43(2), 148-164. https://doi.org/10.1598/RRQ.43.2.3

Han, X., McDougall, J., Mott, C., \& Sudbury, S. (2018). Hunger by the sea: Partnerships in the brave third space. International Journal for Students as Partners, 2(2), 71-84. https://doi.org/10.15173/ijsap.v2i2.3493

Healey, M. (2005). Linking research and teaching: Exploring disciplinary spaces and the role of inquiry-based learning. In R. Barnett (Ed.), Reshaping the University: New Relationships between Research, Scholarship and Teaching (pp. 67-78). New York, NY: Open University Press.

Healey, M., Flint, A., \& Harrington, K. (2014). Engagement through partnership: Students as partners in learning and teaching in higher education. The Higher Education Academy. Retrieved from https://www.heacademy.ac.uk/knowledge-hub/engagement-throughpartnership-students-partners-learning-and-teaching-higher

Healey, M., O'Connor, K. M., \& Broadfoot, P. (2010). Reflections on engaging students in the 
process and product of strategy development for learning, teaching, and assessment: An institutional case study. International Journal for Academic Developers, 15(1), 19-32. https://doi.org/10.1080/13601440903529877

Hodge, D. C., Magolda, M. B. B., \& Haynes, C. A. (2009). Engaged learning enabling self authorship and effective practice. Liberal Education, 95(4), 18-23. Retrieved from https://www.aacu.org/publications-research/periodicals/engaged-learning-enablingself-authorship-and-effective-practice

Jensen, K., \& Bennett, L. (2016). Enhancing teaching and learning through dialogue: A student and staff partnership model. International Journal for Academic Development, 21(1), 41-53. https://doi.org/10.1080/1360144X.2015.1113537

King, H., Kersh, N., Potter, J., \& Pitts, S. (2015). Learner-led and boundary free: Learning across contexts. British Journal of Educational Psychology, Monograph Series II (11), 3950. http://eprints.whiterose.ac.uk/93035/

Levy, P. (2011). Embedding inquiry and research into mainstream higher education: A UK perspective. Council on Undergraduate Research Quarterly, 32(1), 33-39.

Lizzio, A., Wilson, K., \& Simons, R. (2002). University students' perceptions of the learning environment and academic outcomes: Implications for theory and practice. Studies in Higher Education, 27(1), 37-41. https://doi.org/10.1080/03075070120099359

Lopatto, D. (2003). The essential features of undergraduate research. Council on Undergraduate Research Quarterly, (March), 139-142.

Neary, M. (2010). Student as producer: Pedagogy for the avant-garde. Learning Exchange, 1(1), 1-17.

Neary, M. (2012). Student as producer: An institution of the common? Enhancing Learning in the Social Sciences, 4(3), 1-16.

Neary, M. (2016). Student as producer: The struggle for the idea of the university. Other Education: The Journal of Educational Alternatives, 5(1), 89-94. Retrieved from https://www.othereducation.org/index.php/OE/article/view/163

Neary, M., \& Winn, J. (2009). The student as producer: Reinventing the student experience in higher education. In L. Bell, M. Neary, \& H. Stevenson (Eds.), The Future of Higher Education: Policy, Pedagogy and the Student Experience (pp. 192-210). London: Continuum.

Marquis, E., Puri, V., Wan, S., Ahmad, A., Goff, L., Knorr, K., Vassileva, I., \& Woo, J. (2016). Navigating the threshold of student-staff partnerships: a case study from an Ontario teaching and learning institute. International Journal for Academic Development, 21(1), 4-15. https://doi.org/10.1080/1360144X.2015.1113538

McDougall, J., \& Potter, J. (2015). Curating media learning: Towards a porous expertise. ELearning and Digital Media, 12(2), 199-211.

https://doi.org/10.1177/2042753015581975

Perry, R. P., \& Smart, J. C. (2007). Introduction to the scholarship of teaching and learning in higher education: An evidence-based perspective. In R. P. Perry \& J. C. Smart (Eds.), The scholarship of teaching and learning in higher education: An evidence-based perspective (pp. 1-8). Dordrecht: Springer Netherlands. https://doi.org/10.1007/14020-5742-3

Peters, J., \& Mathias, L. (2018). Enacting student partnership as though we really mean it: Some Freirean principles for a pedagogy of partnership. International Journal for Students as Partners, 2(2), 53-70. https://doi.org/10.15173/ijsap.v2i2.3509

Pitts, M. J., \& Brooks, C. F. (2017). Critical pedagogy, internationalisation, and a third space: 
Cultural tensions revealed in students' discourse. Journal of Multilingual and Multicultural Development, 38(3), 251-267. https://doi.org/10.1080/01434632.2015.1134553

Potter, J., \& McDougall, J. (2017). Porous expertise and powerful knowledge. In Digital Media, Culture and Education (pp. 83-106). London: Palgrave Macmillan UK. https://doi.org/10.1057/978-1-137-55315-7 5

Routledge, P. (1996). The third space as critical engagement. Antipode, 28(4), 399-419. https://doi.org/10.1111/i.1467-8330.1996.tb00533.x

Shor, I., \& Freire, P. (1987). What is the "dialogical method" of teaching? Journal of Education, 169(3), 11-31.

Turner, V. (1974). Dramas, fields, and metaphors: Symbolic action in human society. Ithaca, NY: Cornell University Press.

Wallin, P., Adawi, T., \& Gold, J. (2017). Linking teaching and research in an undergraduate course and exploring student learning experiences. European Journal of Engineering Education, 42(1), 58-74. https://doi.org/10.1080/03043797.2016.1193125

Wallin, P., Lyng, R., Sortland, B., \& Veine, S. (2017). Experts in teamwork - A large scale course for interdisciplinary learning and collaboration. Proceedings of the 13th International CDIO Conference, Calgary, Canada (pp. 1-11). Calgary, Canada: University of Calgary.

Werder, C., Thibou, S., \& Kaufer, B. (2012). Students as co-inquirers: A requisite threshold concept in educational development? The Journal of Faculty Development, 26(3), 3438. 